\title{
KELAYAKAN EKONOMI BUDIDAYA NILAM (Pogostemon cablin) DI DESA PUUNDOHO KECAMATAN PAKUE UTARA KABUPATEN KOLAKA UTARA
}

\author{
Syamsuri ${ }^{1 *}$, Hasria Alang ${ }^{2)}$ \\ ${ }^{1}$ Pendidikan Ekonomi, FKIP, Universitas Tanjungpura \\ ${ }^{2}$ Biologi STKIP Pembangunan Indonesia Makassar \\ *Corresponding author: syamsuri@untan.ac.id
}

To cite this article:

Syamsuri, S., \& Alang, H. (2021). Kelayakan Ekonomi Budidaya Nilam (Pogostemon cablin) di Desa Puundoho Kecamatan Pakue Utara Kabupaten Kolaka Utara. JIA (Jurnal IImiah Agribisnis) : Jurnal Agribisnis dan IImu Sosial Ekonomi Pertanian, 6(5), 158 - 163. doi:http://dx.doi.org/10.37149/jia.v6i5.20417

Received: September 02, 2021; Accepted: September 20, 2021; Published: September 22, 2021

\section{ABSTRACT}

Economic potential is the capacity of an area that contains potential resources, both natural resources and human resources, to be developed and become an opportunity in improving the community's economy by looking at the real income of the people in that place. One way that can be done to improve the community's economy is optimizing the superior plants in the area. Economic development can be done by maximizing the effect of commodities that already exist and cultivated for a long time. Puundoho Village is one of the villages with superior crops grown, namely Patchouli. Patchouli oil has high economic value because it contains compounds, terpenoids, phytosterols, flavonoids, organic acids, lignin, alkaloids, glycosides, alcohol, and aldehydes are used in the health and cosmetic fields. The purpose of the study was to see the feasibility of the economic potential of Patchouli (P. cablin) in Puundoho Village using Analisis Revenue Cost Ratio (R/C). The research was conducted from January to February 2021. The method used in this research is qualitative and quantitative. It was collecting data through observation and interviews. The results ratio showed 5,86, so it can be interpreted that Patchouli Industry is feasible to develop.

Keywords: acclimatization; economic potential; patchouli industry; Puundoho Village

\section{PENDAHULUAN}

Studi kelayakan merupakan kegiatan yang mempelajari dengan mendalam mengenai bisnis yang dijalankan, apakah layak atau tidak layak untuk dilanjutkan (Syahyunan, 2014). Kelayakan ekonomi berkenaan dengan analisis layak tidak layaknya akan potensi ekonomi suatu kegiatan yang dijalankan. Potensi ekonomi merupakan kapasitas suatu daerah atau organisasi yang mengandung potensi sumber daya baik sumber daya alam maupun sumberdaya manusia, untuk dikembangkan dan menjadi peluang dalam peningkatan ekonomi masyarakat atau nilai tambah. Setiap daerah mempunyai produk atau tanaman unggulan yang menjadi potensi ekonomi bagi masyarakat di daerah tersebut. Seperti halnya di Desa Puundoho Kecamatan Pakue Utara Kabupaten Kolaka Utara. Juga memiliki tanaman unggulan yang dibudidayakan di tersebut, yaitu Tanaman Nilam. Tanaman Nilam atau Pogostemon cablin memiliki peluang ekonomi yang sangat penting. Hal ini dikarenakan tanaman tersebut dapat menghasilkan minyak atsiri yang disebut minyak nilam atau patchouli oil (Supendy, 2016); (Kemala et al., 2017). Minyak nilam diperoleh dari penyulingan daun, batang dan cabang tanaman nilam.

Tanaman nilam menjadi salah satu komoditas ekspor terbesar di Indonesia dan minyak atsiri yang diperoleh dari tanaman tersebut, menjadikan Indonesia sebagai pemasok minyak nilam terbesar di pasaran dunia (van Beek, T. A., \& Joulain, 2017); (Silalahi, 2019). Keberadaan senyawa terpenoid, pitosterol, flavonoid, asam organik, lignin, alkaloid, glikosida, alkohol, dan aldehida pada minyak nilam, menyebabkan tanaman ini memiliki peluang ekonomi yang sangat menjanjikan karena dimanfaatkan dalam industri parfum, kosmetik, sabun, deterjen, meredakan depresi, stres, menenangkan saraf, mengontrol nafsu makan dan meningkatkan minat seksual (Harunsyah, 2011); (Swamy, M. K., \& Sinniah, 2015). Selain itu, (Silalahi, M., \& Nisyawati, 2018) juga menyatakan bahwa 
tanaman nilam merupakan salah satu bahan utama yang digunakan untuk sauna tradisional oleh etnis Batak di Sumatera Utara.

Tanaman nilam di Indonesia merupakan pertanaman rakyat. Salah satu pertanaman rakyat yang merupakan penghasil nilam berada di Kabupaten Kolaka Utara. Hal ini dikarenakan kondisi tanah di daerah tersebut sesuai dengan tanaman nilam dan menyebabkan masyarakat giat menanam nilam untuk mengganti tanaman kakao yang produktivitasnya semakin menurun (Supendy, 2016). Desa Puundoho, adalah satu desa di Kolaka Utara dimana mata pencaharian penduduknya bertani, dan tanaman nilam merupakan komoditas yang paling banyak dibudidayakan serta merupakan produk unggulan di desa tersebut. Hal ini dikarenakan tanaman nilam memiliki umur atau masa yang pendek dan dapat ditanam secara tumpang sari ataupun sebagai tanaman sela, sehingga dapat meningkatkan pendapatan penduduk.

Pengembangan ekonomi di Desa Puundoho dapat dilakukan dengan mengoptimalkan pengembangan komoditi unggulannya, seperti tanaman nilam, karena tanaman tersebut telah lama dibudidayakan oleh masyarakat setempat. Cara ini tentu dapat meningkatkan kualitas dan kesejahteraan hidup masyarakat (Sukriyanto, 2003); (Zubaedi, 2016). Hal ini sesuai dengan (Rusdiana, S., \& Adawiyah, 2013) yang menyatakan bahwa salah satu strategi pembangunan pedesaan yaitu pembangunan pada sektor ekonominya yang diukur dari pendapatan riil masyarakat.

Beberapa penelitian terkait potensi ekonomi dan kelayakan tanaman nilam telah dilakukan diberbagai daerah. Penelitian (Supendy, 2016) menyatakan bahwa usahan nilam di Desa Babamolingku Kabupaten Bombana sangat layak dikembangkan dengan ratio B/C sebesar 2,4. Penelitian (Taha \& Alam, 2016) di Desa Lumbutarombo Kabupaten Donggala menyatakan bahwa usaha nilam sangat layak dilakukan ditempat tersebut dengan ratio $B / C$ sebesar 1,18 . Sedangkan penelitian (Kemala, N., Wulandari, S. A. \& Julizendri, 2017) di di Desa Muara Madras Kecamatan Jangkat Kabupaten Merangin juga menyatakan bahwa usaha tani nilam ditempat tersebut sangat layak dikembangkan dengan ration $\mathrm{B} / \mathrm{C}$ sebesar 2,13.

Kolaka utara merupakan salah satu daerah yang membudidayakan tanaman nilam. Hal ini dikarenakan kondisi tanah di daerah tersebut sesuai dengan syarat tumbuh tanaman nilam. Masyarakat menanam nilam untuk mengganti tanaman kakao yang semakin turun produktivitasnya akibat serangan PBK atau penyakit buah kakao (Supendy, 2016). Tidak terkecuali Desa Puundoho. Masyarakat di desa ini juga berlomba membudidayakan tanaman nilam, namun analisis kelayakan ekonomi tanaman nilam di desa tersebut belum pernah dilakukan. Tujuan penelitian ini adalah untuk mengetahui kelayakan ekonomi budidaya nilam ( $P$. cablin) di Desa Puundoho berdasarkan kriteria nilai ratio Gros B/C nya.

\section{MATERI DAN METODE}

Penelitian ini dilaksanakan di Desa Puundoho Kecamatan Pakue Utara Kabupaten Kolaka Utara. Pemilihan lokasi penelitian dilakukan karena sebagian besar penduduk di daerah tersebut, merupakan petani yang membudidayakan tanaman nilam. Penelitian ini dilaksanakan selama dua bulan, yaitu Januari hingga Februari 2021.

Variabel pada penelitian ini yaitu kelayakan ekonomi budidaya tanaman nilam. Teknik pengumpulan data pada penelitian dilakukan melalui wawancara yang mendalam kepada informan, observasi dan dokumentasi. Pengambilan informan dilakukan secara purposive sampling (sengaja) yaitu 25 responden dari masyarakat sebagai petani nilam.

Analisis data dilakukan secara kualitatif dan kuantitatif. Analisis data kualitatif disajikan dalam bentuk deskriptif, yakni untuk menggambarkan keadaan, dan kondisi serta fenomena budidaya tanaman nilam di lapangan berdasarkan fakta empiris, sedangkan analisis data kuantitatif yaitu untuk melihat kelayakan dari budidaya nilam tersebut. Analisis kelayakan dihitung menggunakan rumus (Kadariah, 1988); (Nugroho, et.al, 2015) yaitu

$$
A=\frac{\text { Total Penerimaan }}{\text { Biaya Produksi }}
$$

Kaidah keputusan yaitu $A=1$ : artinya usaha tani nilam tersebut impas atau berada pada titik balik normal, $A>1$ : artinya usaha tani nilam menguntungkan dan layak untuk diusahakan, $A<1$ : artinya usaha tani nilam rugi dan tidak layak untuk diusahakan 


\section{HASIL DAN PEMBAHASAN}

\section{Karakteristik Responden}

Responden petani budidaya nilam pada penelitian ini berjumlah 25 orang. Identitas responden yang digunakan dalam penelitian ini terlihat pada tabel 1. Dalam usaha kegiatan bertani, umur, jenis kelamin, tingkat pendidikan dan luas lahan garapan memiliki pengaruh yang sangat penting. Umur dan jenis kelamin berpengaruh terhadap kemampuan fisik di mana kemampuan fisik akan berkurang seiring bertambahnya usia. Pendidikan juga memiliki pengaruh yang sangat besar pada usaha bertani. Pendidikan seseorang akan memengaruhi perilakunya dalam menganalisis dan mengatasi masalah. Lahan garapan juga memiliki peran yang sangat penting, di mana semakin luas lahan garapan, maka peluang untuk memperoleh hasil akan semakin besar (Satriawan, 2013); (Kemala, N., Wulandari, S. A. \& Julizendri, 2017).

Tabel 1. Karakteristik responden

\begin{tabular}{ccc}
\hline No & Karakteristik & Keterangan \\
\hline 1. & Jenis kelamin & $35-55$ tahun \\
2. & Usia & $90 \%$ laki-laki, $5 \%$ perempuan \\
3. & Pendidikan & \\
& SD & $5 \%$ \\
& SMA & $90 \%$ \\
4. & Sarjana & $5 \%$ \\
\hline
\end{tabular}

Sumber : Data Primer Setelah Diolah, 2021

Hasil observasi lapangan dan wawancara dengan beberapa petani di desa Puundoho menyatakan bahwa budidaya tanaman nilam di desa tersebut dilakukan dengan cara pembibitan dan sistem tanam langsung. Sistem tanam langsung yang mereka gunakan yaitu memanfaatkan gelas bekas air minuman kemasan (Gambar 1).

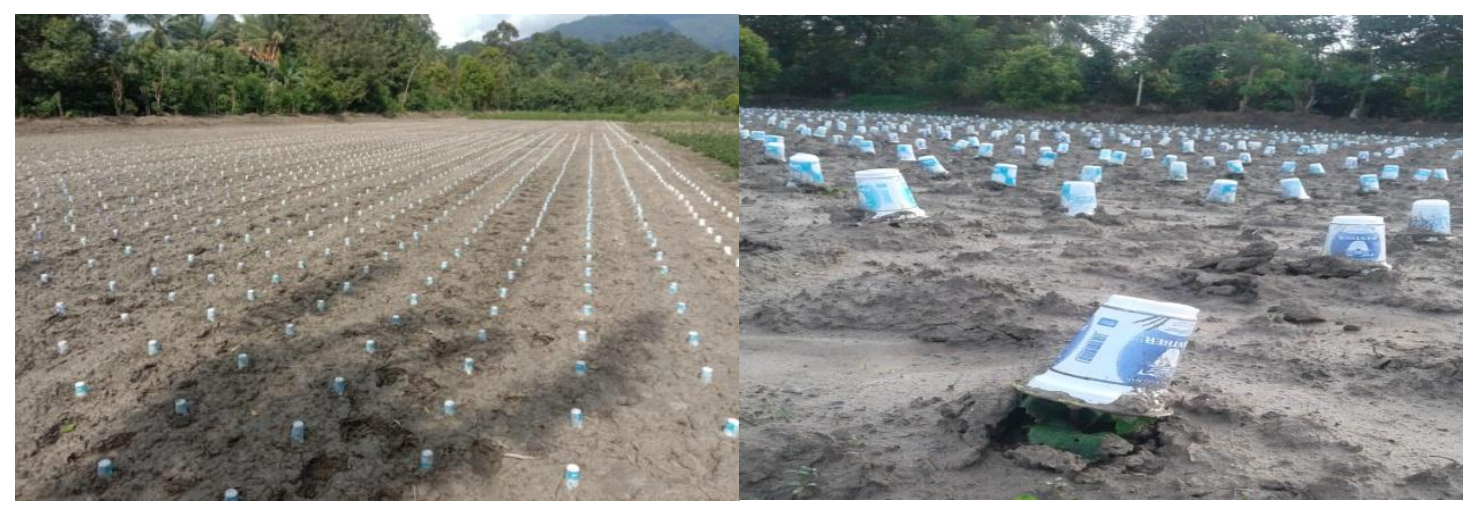

Gambar 1. (A) Penamanan menggunakan gelas bekas air minuman kemasan; (B) Proses Aklimatisasi

Setelah berumur 10 hingga 15 hari, tanaman nilam akan diaklimatisasi dengan cara membuka penutup namun tidak dilepas (Gambar 1). Proses aklimatisasi ini berlangsung 5-7 hari. Wawancara dengan responden menyebutkan bahwa jarak tanam nilam umumnya adalah $70 \times 50 \mathrm{~cm}$. Jika lebih tebal, maka umur panen juga akan lebih cepat. Namun kekurangannya, semakin rapat jarak tanam pada lahan, menyebabkan akan semakin banyak daun yang busuk. Hal ini akan memengaruhi jumlah minyak (kadar persen) nilam yang dihasilkan.

Lebih lanjut, petani menyatakan bahwa penanaman nilam di desa Puundoho dilakukan secara monokultur, tumpang sari, dan tanaman sela. Penanaman secara monokultur akan memberikan hasil yang lebih baik dibandingkan dengan sistem tumpangsari. Hal ini dikarenakan sistem tanam monokultur akan memberikan cahaya yang maksimal pada tanaman nilam. Cahaya sangat berpengaruh terhadap pertumbuhan tanaman. Pada tanaman nilam, cahaya akan mempengaruhi gerak tanaman tersebut. Cahaya yang maksimal ini menyebabkan ruas-ruas tanaman nilam menjadi lebih pendek dan tebal sehingga tangkai yang terbentuk akan semakin banyak. Hal ini menyebabkan jumlah daun yang terbentuk akan semakin banyak pula, di mana daun merupakan 
sumber utama minyak nilam (Gambar 2). Penanaman dengan sistem tumpang sari menyebabkan nilam akan ternaungi. Naungan ini menyebabkan ruas-ruas tanaman nilam akan semakin panjang sehingga tangkai yang terbentukpun akan kurang atau sedikit jumlahnya. Hal ini menyebabkan jumlah daun yang terbentuk akan semakin sedikit pula. Hal ini dikarenakan adanya gerakan fototropisme pada tanaman nilam tersebut. Fototropisme adalah gerak tropisme yang disebabkan oleh rangsangan cahaya matahari (Wiraatmaja, 2017). Sebagai tanaman sela hampir sama dengan tumpang sari. Tanaman sela biasanya dilakukan pada perkebunan coklat yang masih kecil.

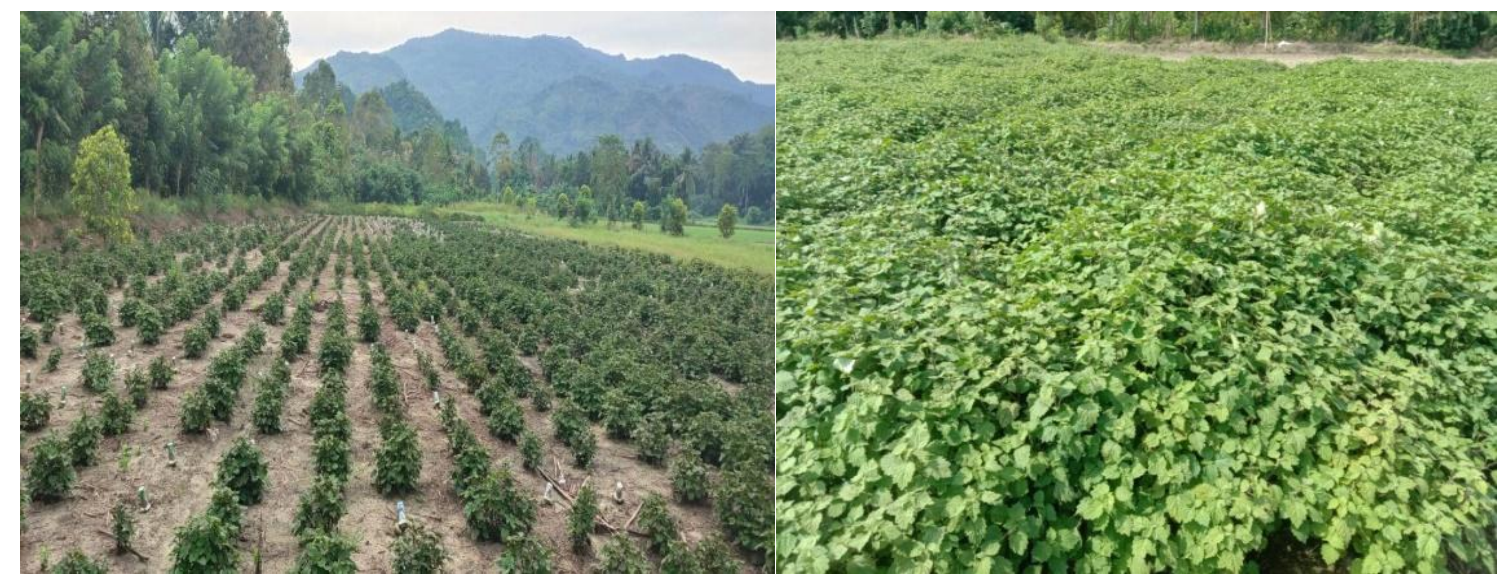

Gambar 2. Sistem Tanam Monokultur

\section{Pendapatan dan Kelayakan Budidaya Nilam di Desa Puundoho}

Hasil wawancara dengan petani nilam di desa Puundoho menyebutkan bahwa komponen biaya operasional pada petani nilam terdiri dari biaya penanaman berkisar Rp. 2.000.000/hektar, pemeliharaan (pupuk dan hama) berkisar Rp. 1.200.000/hektar, biaya panen berkisar Rp. 2.000.000/hektar, biaya penyulingan (sewa ketel) berkisar Rp. 2.600.000/hektar dan biaya buruh penyuling Rp. 250.000 ribu/hektar, sedangkan sewa lahan tidak ada karena lahan adalah milik sendiri. Sehingga rata-rata komponen biaya produksi berkisar Rp. 8.050.000 juta/hektar pertahun dan pendapatan rata-rata Rp. 47.250 .000 (jika harga minyak berkisar Rp. 450.000), atau rata-rata keuntungan Rp. 39.200.000 per tahun.

Tabel 2. Pendapatan budidaya tanaman nilam

\begin{tabular}{clc}
\hline No & \multicolumn{1}{c}{ Uraian } & Pendapatan (Rp/hektar pertahun) \\
\hline 1. & Penerimaan total budidaya nilam & 47.250 .000 \\
2. & $\begin{array}{l}\text { Biaya total budidaya nilam (biaya } \\
\text { produksi) } \\
\text { Keuntungan }\end{array}$ & 8.050 .000 \\
\hline
\end{tabular}

Sumber : Data Primer Setelah Diolah, 2021

Berdasarkan Tabel 2 tersebut, diketahui bahwa penerimaan petani budidaya nilam perhektar Rp. 47.250.000/tahun, dan biaya operasional total perhektar Rp. 8.050.000/tahun. Maka nilai ratio budidaya tanaman nilam yaitu 5,86. Nilai ratio adalah suatu analisis yang digunakan untuk mengetahui apakah kegiatan usaha yang sedang dilakukan layak untuk dijalankan atau diteruskan, dengan ketentuan a > 1 (Kemala, N., Wulandari, S. A. \& Julizendri, 2017). Untuk mengetahui kelayakan suatu usaha, maka digunakan perhitungan yaitu membandingkan total penerimaan dengan total biaya yang dikeluarkan (Taha \& Alam, 2016); (Supendy, 2016). Rata-rata biaya total budidaya tanaman nilam tiap hektar adalah Rp. 47.250.000/tahun, sedangkan biaya produksi tiap hektar adalah 8.050 .000 /tahun. Hasil perhitungan menunjukkan nilai ratio diperoleh 5,86 , yang artinya setiap pengeluaran biaya produksi sebesar $\mathrm{Rp}$. 1 akan menghasilkan penerimaan sebesar 5,86 . Nilai ratio tersebut menunjukkan bahwa a $>1$, maka hal ini berarti bahwa usaha budidaya tanaman nilam di Desa Puundoho memperoleh keuntungan dan layak untuk dijalankan atau diteruskan. 

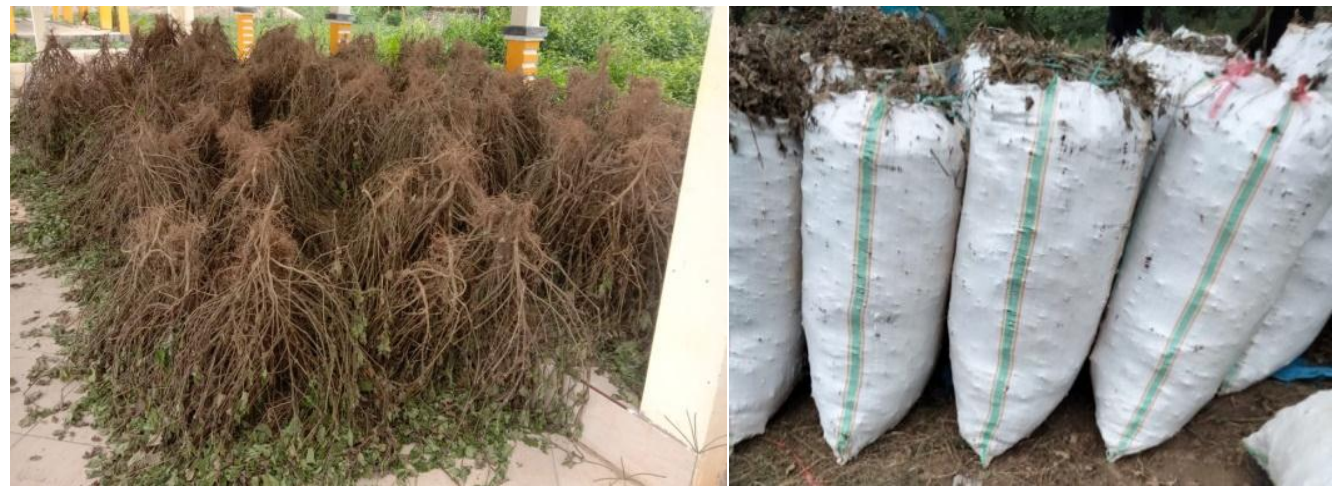

Gambar 3. Proses pengeringan nilam dan nilam yang siap ditimbang/suling

\section{KESIMPULAN DAN SARAN}

Berdasarkan hasil penelitian, maka dapat disimpulkan: bahwa keuntungan petani budidaya tanaman nilam setiap hektarnya rata-rata $\mathrm{Rp} \mathrm{39.200.000/tahun..} \mathrm{Budidaya} \mathrm{tanaman} \mathrm{nilam} \mathrm{di} \mathrm{Desa}$ Puundoho layak untuk dilakukan karena nilai a $>1$ yaitu sebesar 5,86 . Sebaiknya, masyarakat diberi edukasi terkait jenis-jenis atau penamaan nilam yang benar karena karena selama ini, penamaan nilam hanya bersifat kedaerahan (lokal)

\section{UCAPAN TERIMA KASIH}

Tim penelitian mengucapkan terima kasih kepada petani nilam di Desa Puundoho yang telah bersedia menjadi informan dan memberikan data terkait yang dibutuhkan oleh tim peneliti.

\section{REFERENSI}

Harunsyah. (2011). Peningkatan Mutu Minyak Nilam Rakyat Melalui Proses Pemurnian. Jurnal Teknologi, 11(1), 1-7.

Kadariah. (1988). Evaluasi Proyek Analisis Ekonomi. Lembaga Penerbit Fakultas Ekonomi Universitas Indonesia.

Kemala, N., Wulandari, S. A. \& Julizendri, R. (2017). Anaisis Ekonomi Usahatani Nilam Didesa Muara Madras Kecamatan Jangkat Kabupaten Merangin Provinsi Jambi. Mea.Unbari.Ac.ld, 2(1), 35-44. http://mea.unbari.ac.id/index.php/MEA/article/view/16

Nugroho, A., Rohmah, F., Al Rosyid, A. H., \& Suratiyah, K. (2015). Faktor yang Mempengaruhi Produksi dan Pendapatan Petani Kedelai di Kecamatan Paliyan Gunungkidul. In faperta.ugm.ac.id. Jurusan Sosial Ekonomi Pertanian Fakultas Pertanian Universitas Gajah Mada. http://faperta.ugm.ac.id/dies/download/Contoh penulisan makalah Seminar Dies Natalis 69 Faperta.pdf

Rusdiana, S., \& Adawiyah, C. R. (2013). Analisis Ekonomi dan Prospek Usaha Tanaman dan Ternak Sapi di Lahan Perkebunan Kelapa. Jurnal.Uns.Ac.ld, 10(1), 118-131. https://jurnal.uns.ac.id/sepa/article/view/14118

Satriawan, H. (2013). Karakteristik dan prospek ekonomi sistem agroforestri di Kabupaten Bireuen Aceh. Lentera: Jurnal Ilmiah Sains Dan Teknologi, 13(2), 149420. https://media.neliti.com/media/publications/149420-ID-karakteristik-dan-prospek-ekonomisistem.pdf

Silalahi, M., \& Nisyawati, N. (2018). The ethnobotanical study of edible and medicinal plants in the home garden of Batak Karo sub-ethnic in North Sumatra, Indonesia. Smujo.ld, 19(1), 229238. https://smujo.id/biodiv/article/view/2355

Silalahi, M. (2019). Botani, Manfaat, dan Bioaktivitas Nilam Pogostemon cablin. Repository.Uki.Ac.ld, 4(1), 29-40. http://repository.uki.ac.id/id/eprint/811

Sukriyanto. (2003). Pengembangan Masyarakat Islam Agama, Sosial, Ekonomi dan Budaya. Populis Jurnal Pengembangan Masyarakat, 3(1).

Supendy, R. (2016). Analisis Ekonomi dan Manajemen Perbaikan Sistem Usahatani Nilam di Desa Kabupaten Bombana Sulawesi Tenggara (Kasus di Desa Babamolingku). Jurnal.Untad.Ac.ld, 23(2), 164 - 173. http://jurnal.untad.ac.id/jurnal/index.php/AGROLAND/article/view/8373

Swamy, M. K., \& Sinniah, U. R. (2015). A comprehensive review on the phytochemical constituents 
and pharmacological activities of Pogostemon cablin Benth.: an aromatic medicinal plant of industrial. Mdpi.Com, 20(5), 8521-8547. https://doi.org/10.3390/molecules20058521

Syahyunan. (2014). Studi Kelayakan Bisnis. Penerbit USU Press.

Taha, A., \& Alam, M. (2016). Analisis Pendapatan dan Kelayakan USAha Industri Minyak Nilam di Desa Lumbutarombo Kecamatan Banawa Selatan Kabupaten Donggala. In Doctoral dissertation, Tadulako University. https://www.neliti.com/publications/241813/analisispendapatan-dan-kelayakan-usaha-industri-minyak-nilam-di-desa-lumbutarom

van Beek, T. A., \& Joulain, D. (2017). The essential oil of patchouli, Pogostemon cablin: A review. Wiley Online Library, 33(1), 6-51. https://doi.org/10.1002/ffj.3418

Wiraatmaja, I. W. (2017). Buku Ajar: Gerak Pada Tumbuhan. Program Studi Agroekoteknologi Fakultas Pertanian. Universitas Udayana.

Zubaedi, M. (2016). Pengembangan masyarakat: wacana dan praktik. Kencana. https://books.google.com 